\title{
A Multiobjective Power Plant Location Model With Hierarchical Screening: Nuclear Power In Northern Indiana $\uparrow$
}

\author{
Barry D. Solomon, Kingsley E. Haynes, and Andrew J. Krmenec*
}

\section{INTRODUCTION}

The siting of nuclear power plants in the United States has become one of the most controversial aspects of the energy conversion industries. Electric utilities, with a legislative responsibility to supply an ample amount of power for the convenience and necessity of the public, are relying upon increasingly large, coal-fired or nuclear power plants to meet the needs of regional service areas. A single, large power plant (e.g., 650 megawatt electric MW(e) or greater) represents a major capital outlay for the utility company, usually costing well over $\$ 1$ billion. Once constructed, such facilities are expected to be operational for about 25-30 years, and result in major impacts upon the natural and human-built environments. Indeed, a large electric power plant always requires the preparation of a federal environmental impact statement (EIS) before its construction and operation.

A large nuclear power plant is not built to supply electric power to just one city or small region, nor is the plant's environmental impact similarly restricted. A nuclear power plant is usually sited to supply base load electricity as part of a broader regional electric supply grid system. Theoretically, its location is less spatially constrained due to the availability of high voltage electric transmission lines. In practice, however, several factors constrain the siting of nuclear power plants such as water availability for plant cooling, human population density, potential seismic activity and most recently social or political opposition. ${ }^{1}$ Thus, the actual number of potential sites for a nuclear power plant is limited.

Past nuclear power facility siting has often been misguided, failing to consider reasonable constraints on facility location. In the past such fac-

\footnotetext{
†We wish to thank Professor Dale Whittington, Department of City and Regional Planning, University of North Carolina at Chapel Hill and an anonymous referee for their helpful comments and suggestions. We would also like to express our appreciation for the support of the Coastal Energy Impact Program, U.S. Department of Commerce and the Indiana State Planning Services Agency. A shorter version of this paper was presented at the Association of American Geographers Annual Meetings in Los Angeles, Ca, A pril 1981. The views expressed here are those of the authors and not necessarily those of the U.S. Department of Commerce or the Indiana State Planning Services Agency.

*Visiting Assistant Professor of Geography and Mineral Resource Economics, West Virginia University; Professor of Public and Environmental Affairs and Geography; and Ph.D. Candidate in Geography, Indiana University, respectively.
} 
tors as nearby industrial activity, local population density and regional population distribution often have been ignored and occasionally have delayed power plant construction. Recent policy concerns indicate that these are vital and important siting considerations. In the future it is likely that these technological risk issues will be of increasing importance in nuclear power plant siting as a result of Pennsylvania's Three Mile Island accident of March 28, 1979. ${ }^{2}$

Specific examples of some of these issues in facility siting can be illustrated by examining the site of the Bailly Nuclear Unit under construction on the south shore of Lake Michigan at Burns Harbor, in Porter County, Indiana (see Figure 1). This $644 \mathrm{MW}$ (e) reactor, to be cooled with a wet cooling tower, was first planned by the Northern Indiana Public Service Company (NIPSCO) in the mid 1960's as an expansion to an existing coal-fired power plant, but as of May 1,1981 it is only $1 \%$ complete. ${ }^{3}$ The site of Bailly is approximately in the middle of a shore line with intense industrial and energy activity. ${ }^{4}$ Included within a twenty five mile radius of the present site are: steel mills comprising about $25 \%$ of U.S. production capacity; economically linked industries such as industrial gas facilities, metal fabrication plants and major petroleum refineries; and the highly populated metropolitan areas of Gary, Hammond, and East Chicago, Indiana, and Chicago, Illinois. Due to the region's population density and distribution, the present Bailly site recently failed to meet eight out of eight population density criteria recommended by a Nuclear Regulatory Commission panel..$^{5}$ The nature of industrial activity in this immediate locale makes the risk concern even more critical. Many of the industrial facilities employ "hotline" processing which prevents immediate shut-down of operations and evacuation without major structural damage to the capital equipment. The present Bailly site is also adjacent to major recreational resources. In addition to Lake Michigan and its beaches, the Indiana Dunes National Lakeshore and the Indiana Dunes State Park in northern Porter County are heavily used by the residents of this major metropolitan complex.

Recent policy concerned with the minimization of technological risk suggests that the present site of the Bailly Nuclear Unit may be socially non-optimal. Certainly the time and costs associated with over ten years of delay in plant construction implies that an alternative site might be, at least, less conflict ridden and, hence, more suitable. The model presented in this paper is applied to the siting of a nuclear power plant within the NIPSCO service region to meet an exogenously determined hypothetical future peak demand for electricity. This approach will illustrate the type of model which may be appropriate for social policy planning at the local or regional decision level where incremental decision-making is predominant. Future demand is assumed to be centered in the industrial section of northwest Indiana, near the metropolitan complex of Gary, Indiana. The need for a nuclear power plant of a large generation capacity, i.e., as opposed to a similar sized coal-fired power plant or other alternat ves, is also exogenously determined. The objective is to locate the power plant in one of a spatially constrained set of county or sub-county areas in order to 


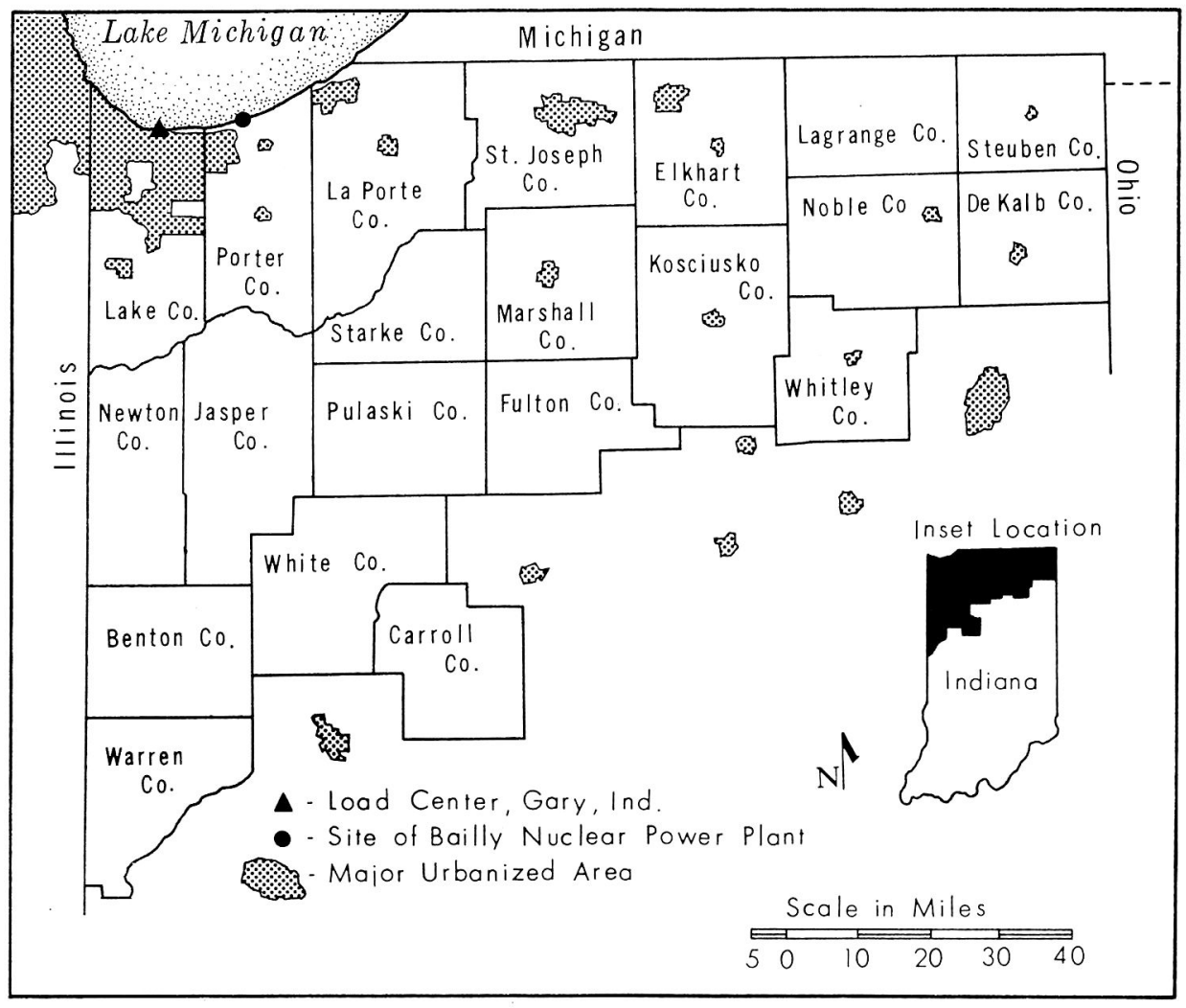

Figure 1. Indiana Counties Considered For Nuclear Power Plant Location

maximize site suitability. For illustrative purposes suitability is represented by four conflicting objective functions: maximize local population compatibility, maximize regional population compatibility, maximize residual water flow from the nuclear reactor's cooling water source and maximize electricity transmission proximity between the plant and the load (demand) center. The dual of the problem would be to minimize location conflict, and hence risk, by trading off these social, environmental and efficiency objectives.

The rest of the paper is organized as follows: after a brief review of related research the power plant location model's structure is described in detail. The outcome of the model's application to northern Indiana is then given, followed by an assessment and evaluation of the model. Finally, the paper ends with a discussion of directions for future research.

\section{RELATED RESEARCH}

Earlier studies have included projections of energy demand and energy facility needs on a national scale; ${ }^{6}$ an examination of regional variation in the demand for energy; ${ }^{7}$ multiobjective location analysis of regional energy facility siting problems; ${ }^{8}$ and water tradeoffs between energy and 
agriculture? Another multiobjective study has assigned probable locations to a large number of hypothetical power plants within a multi-state, mid-Atlantic region of the U.S. ${ }^{10}$ Although this latter approach is interesting it has two major practical shortcomings: there are several uncoordinated siting decision makers at the multi-state level and most power plants are not sited simultaneously, but rather incrementally.

Related work has resulted in the application of a screening algorithm for both coal and nuclear power plants to every county in the United States, which takes the form: ${ }^{11}$

$$
\mathrm{S}_{\mathrm{i}}=\sum_{\mathrm{V}=1}^{\mathrm{N}} \mathrm{C}_{\mathrm{vi}} \mathrm{I}_{\mathrm{V}}
$$

where

$$
\begin{aligned}
& \mathrm{S}_{\mathrm{i}}=\text { suitability score for county } \mathrm{i}, \\
& \mathrm{V}=\text { the siting variable (e.g., population density), } \\
& \mathrm{C}_{\mathrm{vi}}=\text { compatibility index for } \mathrm{V} \text { in county } \mathrm{i} \text {, and } \\
& \mathrm{I}_{\mathrm{v}}=\text { importance weight for variable } \mathrm{V} .
\end{aligned}
$$

Regional siting variables were defined and assigned a weight to indicate each variable's relative influence in the selection of suitable candidate counties for a facility. ${ }^{12}$ Further, each category within each variable was given a compatibility index reflecting its positive or negative influence on facility siting in a given county. The combined weights and compatibility indexes for a given facility type are referred to as a "siting criteria matrix." The variables are continuous and do not change greatly over the area within a county.

The present model is a revision of the siting criteria matrix, formulated as a hierarchical screening and multiobjective programming problem. Some original variables are redefined while others are new. Certain constraints are derived from the original model and others are added. Although this model is limited to a single nuclear power plant, extension to other risky technologies and multiple facility siting presents no theoretical or practical problems. Uses for such models include energy policy analysis, power pool long-range location planning, resource limitation studies, and cumulative environmental impact studies.

\section{MODEL STRUCTURE}

It is assumed that a $650 \mathrm{MW}(\mathrm{e})$ nuclear power plant is needed to meet a future (otherwise unmet) peak demand for electricity centered in Gary, Lake County, Indiana. The owner and operator of the facility will be an electric utility company with the power of eminent domain, serving all or part of a 21 Indiana county region (refer to Figure 1). Thus, a single decision-maker is assumed. Each of these counties is considered as a 
potential site for the plant, although the utility conceivably could site the facility outside its service region and even outside Indiana. These latter two options are unlikely due to transmission and regulatory considerations among other things.

Facility location is first defined as being within a county, without specifying a sub-county site. After screening for suitable counties, a subcounty screening and optimization model is then utilized. Distances to the load (demand) center in Gary are measured from a county's geographic centroid since the population centroid probably would be an incompatible facility locator (in no case does the geographic and population centroid correspond). Constraints and objectives are included for local population compatibility, regional population compatibility, water flow and transmission proximity.

\section{Constraints}

Local Population Compatibility. Population density must be less than 1,000 people per square mile (psm) in order to minimize potential health problems and population displacement costs in case of an evacuation due to a large-scale accident at the nuclear power plant:

$$
\mathrm{PC}_{\mathrm{i}} \leq 999 \text { for all } \mathrm{i}
$$

where $\mathrm{PC}_{\mathrm{i}}$ is the psm in county $\mathrm{i}$.

Regional Population Compatibility. This is the criterion where the population density of spatially lagged county $\mathrm{i}-1$ must be less than 1,000 psm, and where $\mathrm{PC}_{\mathrm{i}}-{ }_{1}$ is the average psm of all counties adjacent to county $\mathrm{i}$.

$$
\mathrm{PC}_{\mathrm{i}-1} \leq 999 \text { for all } \mathrm{i}
$$

Water Flow. Each county i to be considered as a potential site must either be adjacent to Lake Michigan or contain part of a river such that the water withdrawal rate of the facility (in this example about 21 cubic-feet/second) is less than or equal to $15 \%$ of the river's 7 -day 10 -year low flow in cubic-feet/second (cfs), assuming no low flow augmentation: ${ }^{13}$

$$
W W \leq .15 L \text { for all } i
$$

where $\mathrm{WW}$ is the water withdrawal rate of the power plant and $\mathrm{LF}_{\mathrm{i}}$ is the 7-day, 10-year low flow of a river in county $i$.

Transmission Proximity. The transmission proximity from the geographic centroid of county i to Gary, Lake County, must be less than 200 miles due to conflicts with other utility service areas, energy loss (transmission energy loss is estimated to be $1 \%$ of the electricity generated for every 10 miles to transmission), and financial cost considerations:

$$
\mathrm{TP}_{\mathrm{ij}} \leq 199 \text { for all } \mathrm{i}
$$

where $\mathrm{TP}_{\mathrm{ij}}$ is the transmission proximity from county $\mathrm{i}$ to Gary. 
The seismic activity of county i also can be very important. Since all of the counties presently considered are low seismic activity areas, seismic activity considerations are not included in this model. But if high risk seismic areas are considered they should be pre-screened from the vector optimization.

Constraints (2) - (4) have been formulated according to the most recent Nuclear Regulatory Commission guidelines or directives on nuclear power plant siting. Specifically, constraints (2) and (3) serve to limit the "at-risk" population within about a 40 mile radius of the power plant site. Existing standards suggest no distance decay in the maximum allowable population density as distance toward the plant decreases (except for the immediate locale). Hence, all counties spatially lagged from the site county are constrained to the same population density as the site county. Constraints (4) and (5) are technical constraints on water flow and transmission distance; (4) serves to limit utility water usage to federal guidelines and (5) serves to limit the site of the plant within the confines of the service region. Operationally these constraints limit analysis of the objective siting function to those geographic areas meeting each of the constraints. In short, the constraints serve to screen out those geographic areas deemed unsuitable,

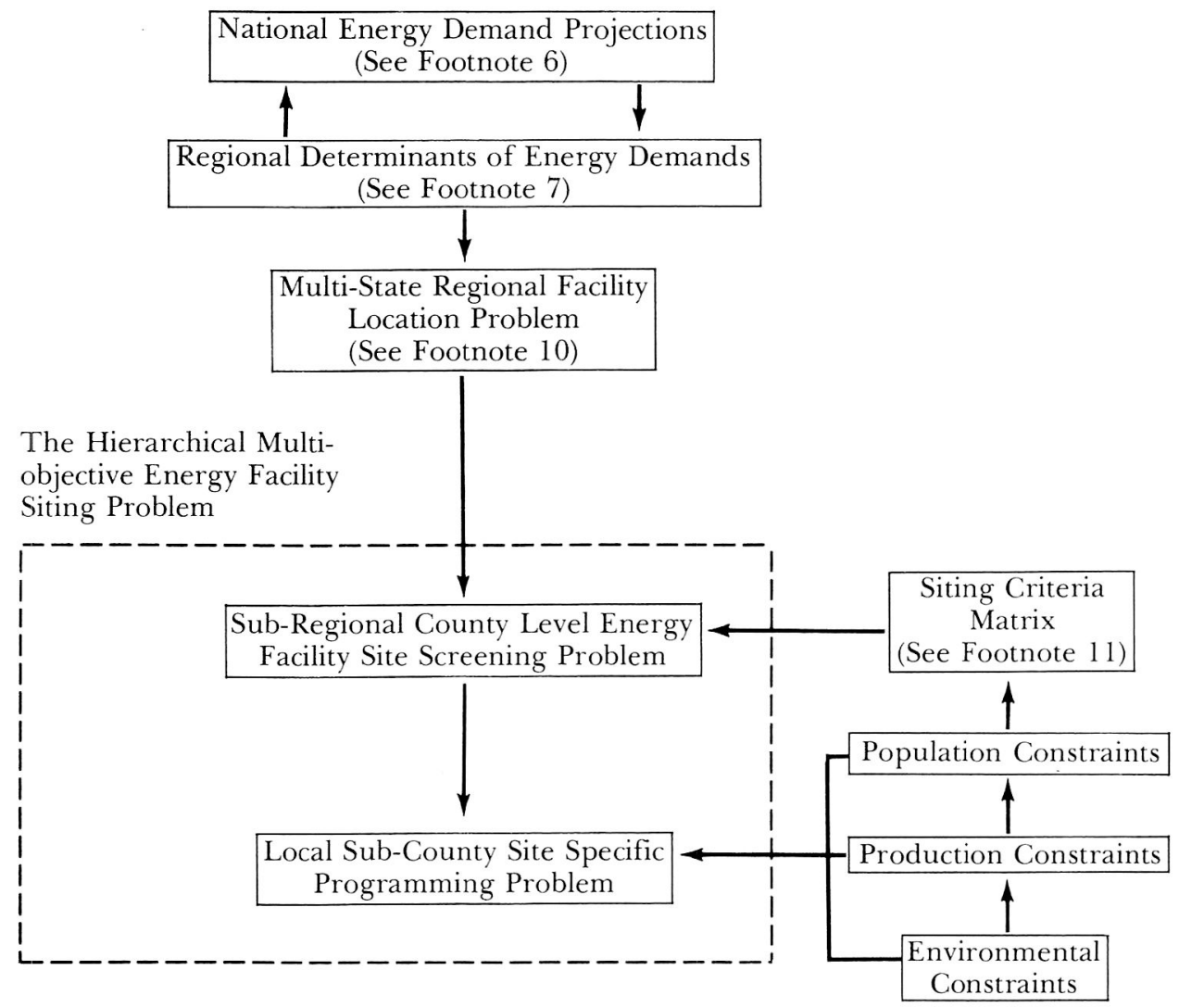

Figure 2. Hierarchical Considerations In Energy Facility Location 


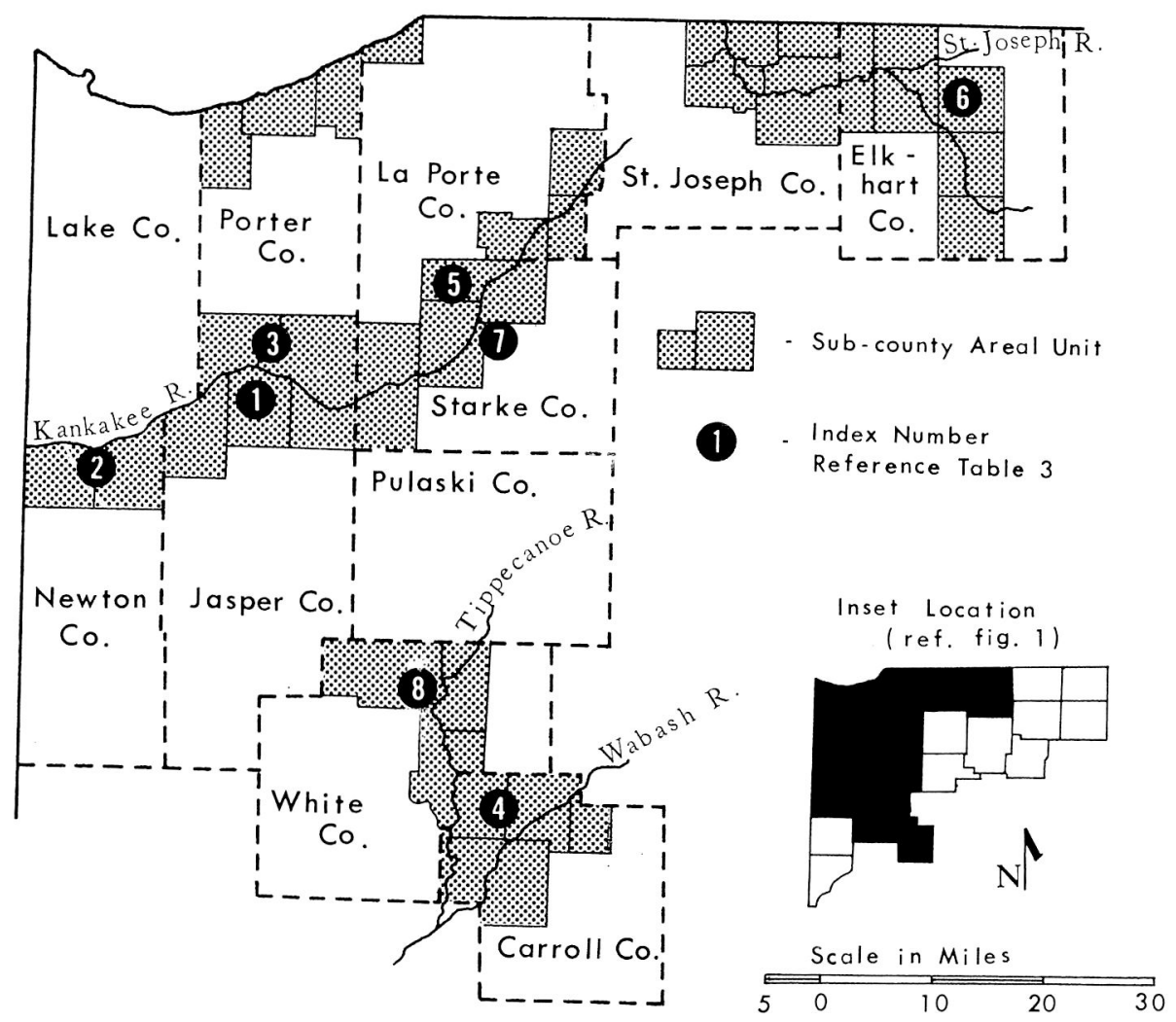

Figure 3. Indiana Sub-County Areal Units Considered For Nuclear Power Plant Location

with respect to physical compatibility, according to current federal limiting guidelines and technical considerations.

After utilizing the county-level screening model, it became apparent that it is also important to consider sub-county areal unit constraints and objectives. For example, the county-level model, by definition, cannot account for the location of people within a county. People often live in large numbers near large bodies of water such as coastlines, lakes or large rivers and nuclear or coal-fired power plants are usually sited adjacent to such water sources for accessible cooling water, leading to local site incompatibility. Thus, a coastal county with a large population distance decay function could have a low "average" total population density, but with most of its people concentrated near the coast. The present model could assign a power plant to such a county, where the facility may be sited in the middle of this large population concentration. The large geographic scale approach also precludes the influence of local level decision makers.

A sub-county areal unit siting analysis has been undertaken in order to bridge the gap between the theory of the model and actual utility company siting practices. This additional analysis is best conceived as a near final 
step in a hierarchy of energy facility siting analyses which might include large regional power pool considerations, individual utility company county facility site screening, and sub-county multiobjective programming analysis (see Figure 2). Since a sub-county siting analysis has been undertaken, it was not necessary to conduct a county level multiobjective programming analysis.

At this scale, the sub-county areal unit for the model is defined to be a group of contiguous townships chosen on the basis of inclusion of or proximity to a water body that meets the county level water flow constraint (see Figure 3). It is hoped that this level of spatial analysis is small enough to be a valid representation of an actual siting decision yet large enough to provide decision-makers flexibility in accounting for any unknown land use conflicts and additional constraints left out of the present model.

Nine of the original 21 counties that were considered for the plant site met the four county level siting constraints: Newton, Jasper, Porter, LaPorte, Starke, St. Joseph, Elkhart, White, and Carroll. Each of these counties has one sub-county areal unit which was subjected to further siting analysis, with the exception of Porter and LaPorte, which have two potential sites. Using the four county level constraints at the sub-county areal unit level, one area each in both LaPorte and St. Joseph counties was eliminated from further analysis due to local population density incompatibility. The area in northern Porter County (the current plant site) was also eliminated since its heavy industrial population and recreational resources present serious locational conflicts for nuclear power plant siting. Neither of these considerations, however, were explicitly accounted for by the present constraints (see section on Assessment and Evaluation).

\section{Objectives}

The multiobjective facility location model includes four objectives. Population density considerations reflect public opinion and the Federal Nuclear Regulatory Commission's recent directive to develop new strict siting regulations requiring construction of nuclear power plants away from densely populated areas. ${ }^{14}$ The water flow objective is an important environmental consideration, and transmission proximity is a conventional financial cost consideration.

Since the scaling metric of the model's four objectives are probably incomparable, the objective values were converted to an integer scale from one to ten for conceptual convenience. Although this changes the analysis to an integer linear programming problem, the results would be comparable if the actual objective values were used.

A best-compromise multiobjective programming solution is identified assuming exogenously determined preference weights (parameters), which may be disputed and subjected to a sensitivity analysis through interactive programming. ${ }^{15}$ It is not intended that the assumed preference weights are to be used for an actual siting analysis and decision. The problem of correct specification of preference weights entails separate issues of its own. ${ }^{16}$ Indeed, some analysts prefer noninferior curve- 
generating (or efficient programming) techniques, and multiple decision-maker amalgamation methods are also possible. ${ }^{17}$ All of these solution techniques have their shortcomings; preference oriented methods exploit the knowledge of preferences, when available, to avoid the large computational costs of the other methods but require large investments of time and money to obtain the preference information.

Local Population Compatibility. Population compatibility of sub-county i is defined to increase as population density decreases:

$$
\text { MAX } \mathrm{PC}_{\mathrm{i}}
$$

where Preference Weight $=1.0$.

Regional Population Compatibility. The regional population compatibility uses the population of spatially lagged sub-county $\mathrm{i}-1$, which is defined to increase as population density in subcounty $\mathrm{i}-1$ decreases:

$$
\text { MAX } \mathrm{PC}_{\mathrm{i}-1}
$$

where Preference Weight $=0.4$ and

the variable values for $\mathrm{PC} \mathrm{i}-1$ are on the same scale as for $\mathrm{PC}_{\mathrm{i}} . \mathrm{PC}_{\mathrm{i}-1}$ is the average psm of all sub-counties adjacent to subcounty i.

Water Flow. The difference between $15 \%$ of the 7 -day, 10-year low flow of a river in sub-county $i$ and the estimated water withdrawal rate of the electric power facility is to be maximized:

$$
\text { MAX RF } F_{i}=.15 \mathrm{LF}_{\mathrm{i}}-\mathrm{WW}
$$

where RF is the residual flow of a river in sub-county $i$, and where Preference Weight $=1.0$.

Transmission Proximity. The transmission proximity from the centroid of sub-county i to the load center in Gary is to be maximized:

$$
\operatorname{MAX} \mathrm{TP}_{\mathrm{ij}}
$$

where Preference Weight $=0.7$.

Another possible objective, suggested by the siting criteria matrix discussed earlier, is to site the facility where a barge pathway, and possibly a railroad, is readily accessible. ${ }^{18}$ This consideration is important during the plant construction phase for movement of the huge nuclear reactor vessel. But this region is adjacent to the Chicago rail hub which has a proliferation of active and abandoned rail lines that appears to make this constraint non-binding. Since the model considers water flow as one of the most important objectives (preference weight $=1.0$ ), sites with the largest water supplies and, hence, sites most amenable to local barge traffic will be favored. Thus, barge related objectives are implicitly included in the model. 
The multiple objectives employed in this analysis serve to minimize locational conflict by minimizing the "at-risk" population while minimizing physical operation costs as well. Objectives (6) and (7), specifically, seek to maximize a social value of site compatability with respect to the at-risk population by minimizing population at risk on a regional scale. The water flow objective, (8), in part seeks to minimize local environmental degradation through the utility's use of water. Objective (8) also has an economic basis. As presently formulated, (8) maximizes residual water flow between $15 \%$ of low flow and utility usage. Maximization of this residual water flow creates the possibility for future industrial expansion in the site region which would benefit from proximity to the power source and has need of a local supply of water. Definition of residual water flow above $15 \%$ of low flow is further in accordance with current federal environmental guidelines on utility water usage. Objective (9), maximization of transmission proximity, is as well part economically and part environmentally founded. Redefined, (9) seeks sites which minimize distance to the load center. Economically, this objective searches for a least transmission cost which is, furthermore, coincident with the least environmental degradation from the construction of transmission lines. By definition these objectives are noncommensurate and cannot be solved simultaneously without the trade-off structure defined by the objective preference weights.

According to the preference weight structure assigned above the muitiple objective siting function employed in this analysis is:

$$
\text { MAX } \mathrm{PC}_{\mathrm{i}}+0.4 \mathrm{PC}_{\mathrm{i}-1}+\mathrm{RF}_{\mathrm{i}}+0.7 \mathrm{TP}_{\mathrm{ij}}
$$

where the notation is as above and subject to the screening constraints. The preference weighting involved in this example places greatest emphasis on local population compatability and residual water flow. Next greatest emphasis is given to transmission proximity and least emphasis is given to regional population compatability. Note that the trade-offs between objective criteria are given explicitly in this formulation, as the value of preference weights. Such a structure as (10) evaluates the objectives and tradeoffs concurrently rather than iteratively, such as in a simple screening analysis. As such the hierarchy of the objectives is stated $a$ priori without subjecting the results to incomplete analysis as might occur with a simple hierarchical screening approach.

\section{OUTCOME}

The application of the model to northern Indiana was undertaken for exploratory purposes. Although the results of the process are instructive and hopefully demonstrate a ready application of multiobjective programming for both analysts and decision-makers, they also suggest some issues of primary consideration if these kinds of methods are to be applied at a more disaggregated level of spatial resolution.

The solution method used follows from the hierarchical or lexicographical approach suggested by van Delft and Nijkamp ${ }^{19}$ and utilized by 
Kitabatake, et al. ${ }^{20}$ In the present application, potential sites are screened first according to compatibility with the constraints in decreasing order of objective function weighting. Thus, all potential sites failing to meet water flow and local population compatibility constraints are first screened out, followed by those sites failing to meet the transmission proximity constraint, and finally those sites failing to meet the regional population compatibility constraint. The outcome of the programming analysis yielded areas in three counties tied as the best compromise solution: Jasper, Newton and Porter (see Table 1). These areas have very low township and surrounding area population densities, relatively ample water supplies from the Kankakee River, and close transmission proximity

\section{TABLE 1}

Objective Data For Eight Sub-County Candidate Areas

\begin{tabular}{|c|c|c|c|c|}
\hline $\begin{array}{l}\text { County } \\
\text { Containing } \\
\text { Candidate } \\
\text { Area }\end{array}$ & $\begin{array}{l}\text { Sub County Unit } \\
\text { Population Density } \\
(1.0)^{\mathrm{c}}\end{array}$ & $\begin{array}{l}\text { Spatially Lagged } \\
\text { Population Density } \\
(0.4)\end{array}$ & $\begin{array}{l}\text { Low Flow }{ }^{\mathrm{d}} \\
(1.0)\end{array}$ & $\begin{array}{l}\text { ransmission } \\
\text { Distance } \\
(0.7)\end{array}$ \\
\hline $\operatorname{Jasper}(1)^{\mathrm{a}}$ & 68.7 & 40.6 & $\begin{array}{c}331 \\
\text { Kankakee River }\end{array}$ & 25 \\
\hline Newton (2) & 56.1 & 58.7 & $\begin{array}{c}413 \\
\text { Kankakee River }\end{array}$ & 30 \\
\hline Porter (3) & 75.8 & 48.0 & $\begin{array}{c}331 \\
\text { Kankakee River }\end{array}$ & 25 \\
\hline Carroll (4) & 55.1 & 69.8 & $\begin{array}{c}221 \\
\text { Wabash River }\end{array}$ & 74 \\
\hline LaPorte (5) & 41.5 & 53.9 & $\begin{array}{c}183 \\
\text { Kankakee River }\end{array}$ & 35 \\
\hline Elkhart (6) & 593.1 & 218.3 & $\begin{array}{c}810 \\
\text { St. Joseph River }\end{array}$ & 77 \\
\hline Starke (7) & 33.9 & 57.3 & $\begin{array}{c}183 \\
\text { Kankakee River }\end{array}$ & 35 \\
\hline White (8) & 97.2 & 25.2 & $\begin{array}{c}181 \\
\text { Tippecanoe River }\end{array}$ & 62 \\
\hline Mean & 127.7 & 71.5 & 331.6 & 45.4 \\
\hline \multicolumn{5}{|c|}{$\begin{array}{l}\text { andex number refers to areas denoted in Figure } 3 . \\
\text { 'Per square mile. } \\
\text { cNumbers in parentheses are preference weights for the objectives. } \\
\text { c7-day, } 10 \text {-year low flow in CFS and water source. } \\
\text { '7 } \\
{ }^{2} \text { To Gary, in miles. }\end{array}$} \\
\hline
\end{tabular}


to the load center in Gary. These areas were far more preferable to the next four groups of townships in Carroll, Elkhart, LaPorte and Starke counties which are, in turn, slightly preferable to an area in White county for the energy conversion facility.

\section{ASSESSMENT AND EVALUATION}

Public outcry over the siting of hazardous industrial facilities has recently emphasized the overall complexity of a needed siting criteria. For facilities such as nuclear power plants, having social as well as environmental impacts, locational siting criteria needs go much beyond simple cost minimization. Instead such siting criteria should maximize compatability with local and regional resources. This type of problem necessarily involves multiple siting criteria (with reference, for example, to at-risk population, the local environment, distance to service centers, and resource needs) with, in many cases, multiple decision-makers or parties of interest. This paper has shown, briefly, the utility of a multiobjective location model for nuclear power plant siting. This approach is particularly well suited to problems involving multiple objectives and a hierarchy of decisionmakers. $^{21}$

The nature of the problem addressed in this paper is similar to that for other hazardous technology siting problems. In such practical problems there generally exist certain federal siting guidelines, state or regional guidelines, and, without the right of eminent domain, local siting standards. The specific siting decision, to the point of single local site, typically involves this hierarchy of siting standards as well as multiple decisionmakers. Such siting problems cannot be simply addressed, as with a screening method, through a hierarchical use of these siting standards as constraints. In particular with multiple decision-makers, arranged hierarchically, there typically exists differing preferences, or trade-offs, between siting objectives. For example, decision-makers at the local level may weight a population compatability criteria more strongly than other criteria, whereas at the regional level economic or environmental criteria may be judged more important. Hence the weighting structure of the multiobjective formulation may differ radically across scales of geographic siting resolution, as do siting standards or constraints. The siting problem in this respect requires an explicit statement of trade-off standards in the problem formulation, which is not obtained through simple hierarchical screening.

In order to provide a general introduction to multiobjective programming as a location model, the siting problem presented here has been greatly simplified. As applied in practice, this model may fail to consider other major siting constraints or objectives as decision criteria. Indeed it can be argued that the model is grossly oversimplified; one can easily suggest other dimensions of siting criteria required for practical operationalization of this model. However, as the dimensionality of the siting problem increases so does the necessity for explicit statement of objective trade-offs. Multiobjective programming is even more suited for such problem formu- 
lations. Again the complexity of these problems, both in dimensionality and in hierarchical structure, precludes screening as a viable analytical tool. And indeed, as evidenced by recent public concern with the siting of hazardous facilities, these problems can no longer be addressed in a simple cost minimization fashion.

\section{DIRECTIONS FOR FUTURE RESEARCH}

The problem addressed in this paper is formulated in a simple static fashion, accordingly, its utility is constrained. Without loss of generality the analytical approach adopted here may be extended to a greater temporal format. As is often the case with the development of new utility nodes other major industrial facilities tend to follow into the region. By considering time, the model can be so formulated as to introduce this possibility as well as changes in population density and distribution and subsequent impacts on local water availability. Although somewhat burdensome, development of the model along a temporal format may be further used for regional planning purposes with respect to siting and also the timing of economic development.

The addition of other dimensions of siting criteria to the location model are necessary for its fruitful practical employment. Identification of the proper objectives to be incorporated in the model is by necessity tied to the type of facility being sited. This to a large degree is a practical problem of model operationalization; however, it is not unreasonable to suggest that the body of hazardous facility siting problems has a general coincident set of siting objectives not particular to any one problem. A summary statement of these common objectives may save much time and expense in practical application of this type of siting analysis. In general it is desirable to balance the construction of the model between an all encompassing validity and pragmatic utility; the multiobjective programming approach affords the advantage of this flexibility. Pragmatic utility can be achieved with further minimal facility-specific additions to a general hazardous facility location siting model. The quantification of these general objective themes and facility-specific objectives serves as a challenge for future multiobjective programming research at all scales of spatial resolution.

More attention needs to be given to the construction of multiobjective programming models that are applicable to local or regional siting decision levels. Too often programming solutions are highly abstract and global in character. Unless specifically applied at the decision level these methods often blur the true applicability of such modeling, not only as a solution method, but also as a framework for a decision process. Multiobjective programming, applied in the hierarchical approach outlined here, holds promise for involving decision-makers at each level with the modeling approach as a means to a solution and also as a structural framework for the decision process. 


\section{FOOTNOTES}

1. See the game theoretic approach to the political opposition problem in Semple, R.K. and Richetto, J.D., "The Location of Electric Energy Facilities: Conflict, Coalition, and Power," Regional Science Perspectives, 9:117-138, (1979)

2. See also discussions of technological risk issues in the psychology literature, such as Viek, C. and Stallen, P. "Rational and Personal Aspects of Risk," Acta Psychologica, 45:273-300 (1980); Slovik, P., Fischoff, B. and Lichtenstein, S. "Cognitive Processes and Societal Risk Taking," in Carroll, J. J. and Payne, J. W., eds., Cognition and Social Behavior. Hillsdale, New Jersey: Lawrence Eribaum, 1976; and Slovik, P. "Judgement, Choice and Societal Risk Taking," in Hammond, K. R., ed., Judgement and Decision in Public Policy Formulation. Boulder, Colorado: Westview Press, 1978.

3. NIPSCO is currently awaiting a Nuclear Regulatory Commission decision on its request for renewal of the Bailly construction permit although some construction may proceed in the interim period.

4. Haynes, K. E., Solomon, B. D., Shapiro, R. W. et al. Energy Facility Siting Review: The Indiana Coastal Zone Management Plan. Final Report to the Office of Coastal Zone Management, NOAA, U.S. Department of Commerce and the Indiana State Planning Services Agency, August 15, 1979.

5. Ingersoll, B. "Bailly A-Plant Flunks Population Density Tests," Chicago Sun-Times, January 13: p. 3 (1981).

6. Brown, D. M. et al., eds. Energy in Transition: 19852010. Final Report of the Committee on Nuclear and Alternative Energy Systems (CONAES), National Academy of Sciences, The National Research Council. San Francisco: W. H. Freeman \& Company, 1980

7. Lakshmanan, T. R. and Anderson, W. "Residential Energy Demand in the U.S.: A Regional Econometric Analysis," Regional Science and Urban Economics, 10:371. 386 (1980).

8. Church, R. L. and Cohon, J. L. Multiobjective Location Analysis of Regional Energy Facility Siting Problems. BNL-50567. Upton, New York: Brookhaven National Laboratory, 1976

9. Guariso, G., Haynes, K. E., Whittington, D. and Younis, M. "Energy, Agriculture, and Water: A Multiobjective Programming Analysis of the Operations of the Aswan High Dam," Environment and Planning A, 12:369-379 (1980).

10. Cohon, J. L., ReVelle, C. S., Current, J., Eagles, T., Eberhart, R. and Church, R. L. "Application of a Multiobjective Facility Location Model to Power Plant Siting in a Six-State Region of the U.S.," Computers and Operations Research, 7:107-123 (1980).

11. Honea, R. B., Hillsman, E. L. and Nader, R. F. Oak Ridge Siting Analysis: A Baseline Assessment Forusing on the National Energy Plan, ORNL/TM-6816. Oak Ridge, Tennessee: Oak Ridge National Laboratory, October, 1979. See also Dobson, J. E. "A Regional Screening Procedure for Land Suitability Analysis," Geographical Review', 69:224-234 (1979).

12. For a discussion of the method used to derive the importance weights for the power plant screening algorithm, see Voelker, A. H. Power Plant Siting: An Application of the Nominal Group Technique, ORNL/NUREG/ TM081. Oak Ridge, Tennessee: Oak Ridge National Laboratory, February, 1977.

13. Suggested by the Nuclear Regulatory Commission, "Nuclear Energy Center Site Survey-1975," Part V, Resource Availability and Site Screening, NUREG-0001. Washington, DC: U.S. Government Printing Office, January, 1976.

14. Public Law 96-295, Section 108 (1980).

15. For an applied example of interactive multiobjective programming, see Nijkamp, P. and Rietveld, P "Multi-Objective Programming Models: New Ways in Regional Decision Making," Regional Science and Urban Econumirs, 6:253-274 (1976)

16. For a good overview of preference weighting methods and their shortcomings, see Hobbs, B. F. and Voelker, A. H. Analytical Multiobjective Decision-Making Techniques and Power Plant Siting: A Survey and Critique, ORNL-5288. Oak Ridge, Tennessee: Oak Ridge National Laboratory, February, 1978.

17. Cohon, J. L. and Marks, D. H. "A Review and Evaluation of Multi-objective Programming Techniques," Water Resources Research, 11:208-220 (1975); Cohon, J. L. Multiobjective Programming and Planning. New York: Academic Press, 1978; Hill, M. and Werczberger, E. "Goal Programming and the Goals Achievement Matrix." International Regional Science Review, 3:165-181 (1978); and Brock, H. W. "The Problem of 'Utility Weights' in Group Preference Aggregation," Operations Research, 28:176-187 (1980)

18. Honea, R. B. et al., op cit.

19. van Delft, A. and Nijkamp, P. "The Use of Hierarchical Optimization Criteria in Regional Planning." Journal of Regional Science, 17: 195-205 (1977). See also Nijkamp, P. Environmental Policy Analysis: Operational Methods and Models. New York: John Wiley \& Sons, 1980

20. Kitabatake, Y., Miyazaki, T. and Takahashi, M. "Regional Multiobjective Planning of Water Supply and the Disposal of Residuals with Due Regard to Intraregional Population Distribution," Environment and Planning $A$. 12:627-648 (1980).

21. See also (harnes, A., Haynes, K. E., Hazelton, J. E. and Ryan, M. J. "A Hierarchical Goal-Programming Approach to Environmental Land Use Management," Geographical Analysis, 7:121-130 (1975). 